\title{
Factor analysis of the labor interests formation of employees in educational institutions
}

\author{
Rudaleva Irina $^{1}$, Kabasheva Irina ${ }^{1 \mathrm{a}}$ and Kovaleva Elvina ${ }^{2}$ \\ ${ }^{1}$ Kazan Federal (Volga region) University, 38 Kremlevskaya St. Kazan, 420008, Russia \\ ${ }^{2}$ Institute of economcs, management and lov, 42 Moskovskaya St. Kazan, 420111, Russia
}

\begin{abstract}
You should leave $8 \mathrm{~mm}$ of space above the abstract and $10 \mathrm{~mm}$ after the abstract. The heading Abstract should be typed in bold 9-point Arial. The body of the abstract should be typed in normal 9-point Times in a single paragraph, immediately following the heading. The text should be set to 1 line spacing. The abstract should be centred across the page, indented $17 \mathrm{~mm}$ from the left and right page margins and justified. It should not normally exceed 200 words.
\end{abstract}

\section{Introduction}

In the conditions of increasing international competition and increasing the quality of goods increases the contribution of each individual employee to the final results of the organization and socio-economic benefits society as a whole. This requires a radically new understanding of the role and tasks of the modern worker and in accordance with the construction of an effective system of motivation and stimulation. The latter supposed an individual approach to worker as a person, the full development of its labour interest and motivation to work better and much higher results.

Labour interest of the organization's staff is provided by the system of interconnected forms and motivational mechanisms actively promoting the satisfaction growth with different parameters of its activities. Therefore, improving staff motivation in the modern understanding assumes first of all to create strengthening and involvement conditions of the interests staff in the efficiency and quality of their work, that promote self-realization of his needs in professional growth, increases organization productivity and profitability.

In the large number of socio-economic research the interest analysis of worker while labour activity is considered in terms of identifying potential prospects for its motivation and incentives. Here the interest of labour appears as a fundamental element in stimulating the overall control system of the organization. This approach seems justified, since incentive mechanisms serve the purpose of reconciling the interests of members of a socio-

${ }^{\text {a }}$ Corresponding author: kaba.73@ mail.ru 
economic system "... and motivations of some elements to commit certain actions in the interests of the other elements or the system in the whole" [1].

At the same time the scientists use a quite variety of approaches and methods to the study of tangible and intangible forms of labour interest stimulation of worker and its effect on the performance of the organization in the whole.

Realizing the incentives of the needs and interests that in the broadest sense is the economic driving force of human activity Andrienko V. and V. Danyuk say that by themselves they do not provide unconditional fulfilment by the people of labor action. Therefore, in the system the driving force should be the elements that are directly linked to the people welfare with the process of work and its results [2].

Zorina N.A. and Akimova E.N. go further and subjected the role analysis of incentives as an instrument of influence on the interests of individual employees [3]. If the economic conditions created by the system of incentives, make the prospect of satisfying personal or collective interest to the real, then appears a material interest in the results of individual or collective work in the public correspond to the necessary parameters. They come to the conclusion that the working interest is the derivative from the system of economic levers and incentives, as a results of its functionality.

This view of Russian economists develops in line with the conclusions of one of the leaders of humanistic psychology Abraham Maslow, who claimed to get maximum return on staff, the company owner is only necessary to adequately interest its in the early achievement of their goals [4].

Continuing this tradition, economists thoroughly investigated the problem of increasing necessities of the staff labor interests in improving the efficiency of the enterprise. It was subjected to test the hypothesis of a favorable effect on the employment of staff interest in collective ownership. Lack of enthusiasm is the most frequently arises where a person does not have enough personal interest in the results of labor. Hence, it was suggested the possibility of obtaining additional income by improving the quality of work that fuels the interest of employees in the growth of the efficiency of the entire enterprise. The study shows that the application of the principles of collective ownership of enterprises «ESOP» corresponds to an increase of the labor interests of employees in the result of their activities and high economic efficiency [5].

In general, it should be noted that the consideration of the workers interests by the labor theory of motivation is in line with the division of their procedural and substantive. Remedial theories of motivation (theory expectations W. Vroom, equity theory S. Adams and comprehensive theory of Porter-Lawler) analyzed how people allocate effort to achieve different purposes, and that it affects the choice of a particular type of behavior [6 and 8]. Under this theory does not dispute the existence of the needs, but it is assumed that people's behaviour is determined not so much by the need, but as a function of their perceptions and expectations related to the specific situation and the possible consequences of the selected type of behaviour.

On the contrary, substantive theory of motivation investigate in the first place people needs, encourage them to take action, especially when determining the work scope and content.

Without going into a critical analysis of the motivation theories, it should be noted that interests of employee performs a very important factor in one and in the other theories reflected in different research on specific factors and the characteristics of the labour process.

A modern interpretation of the procedural theory of motivation, develops famous economist J. Pink. [9]. It proves the need to switch the motivation from external incentives (among which is the main material rewards) on the internal - the most significant of which is the full disclosure of interest in the work of man. In his opinion, remuneration, bonuses 
and other forms of result of material incentives in the information age, or useless, or simply harmful to the employees and the firm itself. Financial reward is effective only when algorithm tasks. According to the consulting firm McKinsey \& Co in the US, only $30 \%$ of new jobs associated with algorithm work, and $70 \%$ of people waiting for operations with elements of creativity and analysis. He puts forward the idea of the need to motivate a person to focus on his interest - the natural desire of every human excellence, skill and independence. "Give to a man to obtain satisfaction from the case of creativity and he will reach more than under stimulation by bonuses or recognition. Hence the paramount importance gets the creation of an appropriate conditions and atmosphere in the organization to maximize the fruitful implementation of the qualitative characteristics of a person. In his thoughts he moves further and says that the organization is necessary to employ only those workers who have strong internal motivation - curiosity and independence.

Of course, it looks disputable the relevance glance D.Pink in modern Russia, where worthy wage is viewed more as a "hygiene", and not determining motivating factor (hightech industries, inventive activity, applied sciences, R \& D, etc.) are poorly developed, extremely low productivity, lack of highly skilled labor and management in enterprises and others. However, with the development of the Russian economy on the path of building the information society, these postulates, we think, will become relevant [9].

A similar opinion was voiced earlier by McGregor in the fundamental work "The Human Side of Enterprise", where he proved to have interest to the work "... as natural as play or rest", that inventiveness and creativity peculiar to most people and under appropriate conditions they will be ready to take responsibility and aspire to it [10].

The self-determination theory E.Desi and R. Ryan the person's ability to feel interest is considered to be fundamental on his nature and this ability, according to scientists to develop and strengthen in the labor activity. The universality of the human needs in competence, autonomy and interrelation as a priority need has to be satisfied? Since only in this case we are motivated, productive and happy [11].

Similar results were obtained empirically, when researchers from Cornell University studied 320 small businesses, half of which are based on the internal interests of workers, and gave them greater autonomy, while the other half was based on a rigid vertical control. The enterprise growth index oriented on labor interest were higher in four times, than the same firm indexes focused on monitoring, but the labor turnover indexes were three times less [12]

The fundamental work of industrial-organizational psychology D. Schultz and Schultz S. considering employment category of interest by the versatility of the concept of job satisfaction, keeping in mind the individual characteristics of the activities that can influence the attitude of the performers [13]. They note that under the condition when work provides enough opportunities to experience itself, the work satisfaction will not depend on cognitive abilities. While the number of factors influencing satisfaction and interest of the work in general, it refers congruence organizational justice, the ability to use the skills and personal qualities of the person: the need for professional growth and development, the belief in the work ethic, and the degree of worker participation in decision-making associated with work process.

Modern organizational style that seeks to humanize the working environment has already changed many traditional bureaucratic approaches to managing organizations. An increasing number of organizations related to their employees as an integral and important member of the company and inviting them to participate in long-term planning and decision-making. Such a change in the organizational style has led to cardinal changes in the organization and carrying out the work, which in turn significantly improve the quality of working life of many people. It focuses on activities that should implement modern 
organizations to clearly define their organizational goals, organizational guarantee justice and to support the efforts of staff to a professional growth.

A significant part of research on the labour interests of its staff activity addresses this question in connection with the efficiency of labour. It is noted that the modern perception of the work efficiency is not limited to its direct product. Work will not be considered as effective if staff are not satisfied with the content and remuneration, moral and psychological climate in the team, if the employees are not interested in the contribution to the achievement of organizational goals. This updated the subjective perception of the employment effectiveness make such characteristics of this process as the interest of labour, satisfaction with the process and outcome of labour, involvement of different levels of human development, and the parties in the implementation of activities, "investment" of the subject activity, the tension degree of emotional and psychological functions necessary to achieve the result and etc.

Thus in addition to the vision assessment of employees about self-interest level, a great value of their opinion relatively on the colleagues actions. Therefore, the study of interest by surveying work in the questionnaire included questions related to the relationships in the team, the frequency of disagreements with colleagues, emotional and psychological climate, etc.

Moreover for professions such as "man-man" principle, this factor becomes principled, as carried out with the direct collaboration with other team members. Subjective criteria of work efficiency can vary considerably under the influence of joint activities, interaction between individual members of a social group, which includes health workers, management, and patients. The conclusion of the close dependence of subjective criteria of work efficiency of individual members from interactions in a social group: the satisfaction of the work subject; special relevant to the activity; matching the subject of labour required to his personal characteristics.

\section{Method}

Consideration of the factors appearance of the labour interests of employees serves for identifying problem areas and improvements of advanced developments. Based on the results of the research level of interest in employment, the employer may adjust the activities of the organization, to develop new systems of interaction with the staff, business partners and other stakeholders.

\section{Result and Discussion}

Consider how various factors influence on the formation and development of the employees labour interests of educational institutions (Table 1,2).

Table 1. Model MNC formation of labor interests of employees (used 188 observations)

\begin{tabular}{|c|c|c|c|c|c|}
\hline Variable & Coefficients & $\begin{array}{l}\text { Common } \\
\text { mistake }\end{array}$ & t-statistics & $\begin{array}{c}\mathrm{P}- \\
\text { parameter }\end{array}$ & \\
\hline const & 0,596701 & 0,193659 & 3,0812 & 0,00240 & $* * *$ \\
\hline $\begin{array}{l}\text { Harmonious relationships with } \\
\text { colleagues (v18) }\end{array}$ & 0,146876 & 0,0682733 & 2,1513 & 0,03283 & $* *$ \\
\hline $\begin{array}{l}\text { Compliance with employment } \\
\text { expectations (v19) }\end{array}$ & 0,240056 & 0,0715974 & 3,3529 & 0,00098 & $* * *$ \\
\hline Disagreements with colleagues (v24) & $-0,0841905$ & 0,0329719 & $-2,5534$ & 0,01153 & $* *$ \\
\hline The level of organization of work (v25) & 0,131261 & 0,0577835 & 2,2716 & 0,02434 & $* *$ \\
\hline Job satisfaction (v28) & 0,210277 & 0,0677445 & 3,1040 & 0,00223 & $* * *$ \\
\hline
\end{tabular}


Table 2. Analysis of the model parameters

\begin{tabular}{llll}
\hline Indices & Value & Indices & Value \\
\hline Mean of Dependent Variable & 1,533333 & St. Deviate of Dep. Variable & 0,800838 \\
Residual Sum of Squares & 70,95436 & St. Model Error & 0,638579 \\
R-square & 0,381931 & Corrected R-square & 0,364170 \\
F(8, 143) & 21,50436 & P-value (F) & $1,00 \mathrm{e}-16$ \\
Log Likelihood & $-171,6261$ & Akaike Criterion & 355,2523 \\
Schwarz Criterion & 374,4100 & Hannan-Quinn Criterion & 363,0199 \\
\hline
\end{tabular}

Test White (White) showed that there is no heteroscedasticity.

Test statistics: $\mathrm{LM}=32,6883$.

p-value $=\mathrm{P}($ Хи-squared $(20)>32,6883)=0,0364941$.

Analysis models multicollinearity showed her absence.

The constructed model is a high quality, as the coefficient of determination is 0.3819 , which means that the factors taken into account in the model to explain the formation of $38.19 \%$ interest in the employment of workers. Moreover, the constructed model P-value is $1,00 \mathrm{e}-16$, which also shows its high quality and the probability of error of $1 \%$, thus the degree of reliability of $99 \%$.

So important for workers turned up an appropriate employment expectations (question v19) and job satisfaction (question v28). Ie the formation and development of labor is determined by the interest, first of all, correspondence to the results of work motivational settings. This setting is a kind of barometer of the interests balance of workers and the administration of educational institutions, without which it is impossible to organize an effective learning process.

\section{Conclusion}

In this work the interest depends on the nature of relationships with colleagues. Harmonious relationships with colleagues (question v18) is directly proportional influence on the development of labor interests, and disagreements with colleagues (question v24) form an inverse dependence.

\section{References}

1. Novikov, D., Promotion socio-economic systems / Basic mathematical models. Institute of Control Sciences. 256p (1998)

2. Andriyenko, V. \& Danyuk, V., Economic incentives for labor activity. INFRA (2005)

3. Zorina, N. \& Akimova, E., Incentives to employees as part of the personnel management system. Manager of the company. Vol.8. pp.68-74 (2012)

4. Maslow, A., Motivation and Personality. SPb .: Eurasia. 478p (1999)

5. Sergeev, A., Changes in work motivation of employees in the collective form of property (for example, Plan ESOP). Management of economic systems: an electronic scientific journal. Vol.53 (5). - P.38 (2013)

6. Vroom, V., Work and motivation. N.Y. Wiley, 334 p (1964)

7. Vroom, V., Industrial social psychology. The Handbook of social psychology. Vol 5. N.Y.: Addison-Wesley, pp. 200-208 (1969)

8. Salmon, W., Lawler, E. and others, Corporate Governance. Published by Harvard Business Press, 224 p (2007)

9. Pink, H., Drive: The Surprising Truth About What Motivates Us. Penguin Group, 242 p (2011) 
10. McGregor, D., The Human Side of Enterprise: 25th Anniversary Printing (McGrawHill). pp.33-34 (1985)

11. Ryan, R.M. \& Deci, E.L., Self-Determination Theory and the Facilitation of Intrinsic Motivation, Social Development, Weil-Being, American Psychologist. Vol.55, January, p.68 (2000)

12. Baard, P.P., Deci, E.L. \& Ryan, R.M., Intrinsic Need Satisfaction: A Motivational Basis of Performance and Well-Being in Two Work Settings», Journal of Applied Social Psychology. Vol.34 (2004)

13. Schulz, D. \& Schulz, S., Psychology and work. SPb .: Company "Publishing house" Peter ". 131p (2003) 